\title{
Primary immunodeficiency-related bronchiectasis in adults: comparison with bronchiectasis of other etiologies in a French reference center
}

Hélène Goussault ${ }^{1}$, Hélène Salvator ${ }^{1,2,3^{*}}$ (D), Emilie Catherinot ${ }^{1}$, Marie-Laure Chabi ${ }^{4}$, Colas Tcherakian ${ }^{1}$, Alexandre Chabrol ${ }^{1}$, Morgane Didier ${ }^{1}$, Elisabeth Rivaud ${ }^{1}$, Alain Fischer ${ }^{5,6,7,8}$, Felipe Suarez ${ }^{5,7,9}$, Olivier Hermine ${ }^{5,7,9}$, Fanny Lanternier ${ }^{10}$, Olivier Lortholary ${ }^{5,7,10}$, Nizar Mahlaoui ${ }^{5,6}$, Philippe Devillier ${ }^{1,2,3}$ and Louis-Jean Couderc ${ }^{1,2,3}$

\begin{abstract}
Background: Bronchiectasis is a heterogeneous disease depending on etiology. It represents the most frequent non-infectious pulmonary complication of primary immunodeficiencies (PID). We investigated whether bronchiectasis associated with PID had a distinct course in comparison to bronchiectasis of other causes.

Methods: Retrospective single-center study of adult patients diagnosed with non-cystic fibrosis bronchiectasis with more than 5 years of follow-up and at least 4 pulmonary functional tests available at one year apart. They were divided into three groups: PID- related bronchiectasis, idiopathic/post infectious-related bronchiectasis and other causes of bronchiectasis. Respiratory functional data and clinical outcomes were compared.

Results: Of 329 patients with bronchiectasis diagnosed in Foch Hospital (Suresnes, France), 98 patients fulfilled the selected criteria (20 PID-related cases, 39 idiopathic or post-infectious cases, and 39 cases with other causes). Median time of follow-up was 9.5 years. Groups were similar concerning initial characteristics (female $70.4 \%$, never smokers 59.2\%, mild severity bronchiectasis according to the FACED score and median FEV1 at diagnosis $73.5 \%$ predicted values [Q1-Q3: 53.75-90.5]), except PID patients who were younger (median age of 51.5 vs 62 years, $p=0.02$ ). Eighty-five percent of PID patients received immunoglobulin substitution (median trough level was measured at $10.5 \mathrm{~g} / \mathrm{dl}$ [10;10.92]). Global median FEV1 annual decline was $25.03 \mathrm{ml} /$ year [8.16;43.9] and $19.82 \mathrm{ml} /$ year [16.08;48.02] in the PID patients group. Forty-five percent of patients had bacterial colonization, pneumoniae occurred in $56 \%$ of patients and median exacerbation annual rate was 0.8 [0.3-1.4]. Hemoptysis occurred in 31.6\% of patients. Global mortality rate was $11.2 \%$. We did not record any significant difference for all clinical and functional outcomes between patients with PID and other etiologies. The median decline in FEV1 was similar in the three groups.

Conclusions: The course of PID-related bronchiectasis was similar to bronchiectasis of other causes. Provided that patients receive immunoglobulin replacement, the course of PID-related bronchiectasis seems to be independent of the underlying immune disorder.
\end{abstract}

Keywords: Bronchiectasis, Primary immunodeficiency, Common variable immune deficiency, Immunoglobulins

\footnotetext{
* Correspondence: helene.salvator@gmail.com

${ }^{1}$ Service de Pneumologie, Hôpital Foch, Suresnes, France

${ }^{2}$ Laboratoire de Pharmacologie Respiratoire UPRES EA 220, Universite Paris

Saclay, Versailles, France

Full list of author information is available at the end of the article
}

(c) The Author(s). 2019 Open Access This article is distributed under the terms of the Creative Commons Attribution 4.0 International License (http://creativecommons.org/licenses/by/4.0/), which permits unrestricted use, distribution, and reproduction in any medium, provided you give appropriate credit to the original author(s) and the source, provide a link to the Creative Commons license, and indicate if changes were made. The Creative Commons Public Domain Dedication waiver (http://creativecommons.org/publicdomain/zero/1.0/) applies to the data made available in this article, unless otherwise stated. 


\section{Background}

Bronchiectasis is a chronic respiratory disease, defined radiologically by the presence of permanent bronchial dilatation on high resolution chest computerized tomography.

In recent studies, investigations led to an underlying cause in approximately 40 to $60 \%$ of patients [1-6]. Determination of an etiology is important, as it could result in specific care reported in $13 \%$ of patients [5].

Primary immunodeficiencies (PID) account for $1-17 \%$ of etiologies of patients with bronchiectasis [1-3]. The improvement in their management, mostly immunoglobulin substitution, has allowed us to decrease the prevalence of bacterial pneumoniae and mortality [7-9]. However, bronchiectasis remains the most frequent non-infectious respiratory complication of PID, making its physiopathology unclear and unrelated to the occurrence of previous bacterial pneumonia [10-13].

In bronchiectasis, some factors have been identified as having a poor prognostic value: extension of bronchiectasis [14], chronic obstructive pulmonary disease (COPD) [14] and Pseudomonas aeruginosa colonization [15]. However, little is known about mean-term outcome and changes in pulmonary function. The aim of our study was to compare initial characteristics, complications and prognosis of PID-related bronchiectasis with a large cohort of patients with bronchiectasis due to other causes.

\section{Material and methods}

The study received a favorable opinion from the research protocol evaluation committee of the "Société de Pneumologie de Langue Française” (CEPRO 2018-018).

\section{Patients}

\section{Baseline findings}

We performed a retrospective study of the medical records of all adult patients ( $>18$ years old) diagnosed with bronchiectasis in the Department of Respiratory Medicine of Foch Hospital, Suresnes, France, between 1984 and 2012. Patients selected for the study were those with more than 5 years of follow-up and with at least four lung function tests available at one year apart.

All data were collected between November and December 2017.

Standard management at the diagnosis of bronchiectasis in our center includes determination of blood cell count; liver and kidney functional tests; detection of rheumatoid factor and anticitrullinated protein antibodies, antinuclear antibodies and anti-neutrophil cytoplasmic antibodies (ANCA); HIV serologic test; serum protein electrophoresis, serum IgG, IgA and IgM levels, serum IgG subclass levels, serum IgE level; detection of aspergillus precipitins and aspergillus serologic test; sputum microbiologic examination and culture for bacteria, fungi and mycobacteria. In cases of an unusual clinical presentation or infection with a rare pathogen, we sometimes prescribe additional, targeted immunological analyses. Tests for cystic fibrosis (a sweat chloride assay and/or genetic testing) and for primary ciliary dyskinesia (ciliary ultrastructure analysis or genetic testing) were performed if there was any clinical suspicion (i.e. sterility, diabetes mellitus, sinonasal disease in patients under 40 years of age, situs inversus, or a family history of bronchiectasis). This approach is in line with the guidelines published by the British Thoracic Society [16].

Patients were divided into three groups: primary immunodeficiency; idiopathic and post infectious related bronchiectasis and patients with all other etiologies of bronchiectasis.

Bronchiectasis was defined as of post-infectious origin if there was consistent personal medical history such as pneumonia during childhood or severe whooping cough and no other cause. Bronchiectasis with no cause found at the end of the investigations was defined as idiopathic. Patients with cystic fibrosis (CF) and with traction bronchiectasis related to an interstitial pneumonitis were excluded.

Age at diagnosis (defined by the date of first medical document confirming bronchiectasis), gender, smoking habits (active, former and never smoked), Body Mass Index (BMI), arterial hypertension, gastroesophageal reflux (symptoms or 24-h gastroesophageal $\mathrm{pH}$ monitoring), osteoporosis, diabetes mellitus, treatment by statins, initial severity of bronchiectasis, and results of lung function tests were collected. Bronchiectasis severity was evaluated using the FACED score (including the following variables: FEV1\% predicted, age, chronic colonization by Pseudomonas aeruginosa, radiological extent of the disease, and dyspnea) [17]. The thoracic-CT scans were scored by a trained thoracic radiologist, using the Bhalla score [18]. Thoracic-CT scans were performed in inspiration, with slide sections of 1.5 or $3 \mathrm{~mm}$ thickness. Chronic bronchial colonization was considered when at least two sputum cultures were positive for the same pathogen in an otherwise healthy patient with no worsening of his/her respiratory symptoms and no new chest radiological images.

\section{Follow-up study}

We recorded any prescription of immunomodulatory treatment, including: immunoglobulin substitution, azithromycin (at anti- inflammatory doses, for more than three consecutive months) or omalizumab.

We noted values of respiratory functional test (PFT). At least four PFT results at one year apart were recorded for each patient. Obstruction was defined as FEV1 on vital capacity rate $(\mathrm{VC})<70 \%$. Distension was defined as residual volume (RV) on total lung capacity rate (TLC) $>30 \%$.

We identified each of the following events:

- Respiratory exacerbations, defined as a requirement for antibiotics due to one or more of the following 
symptoms: increasing sputum volume, worsening sputum purulence, worsening dyspnea, fever, hemoptysis, increased fatigue/malaise.

- Pneumoniae, defined as the presence of radiological opacities associated with signs of exacerbation

- Hemoptysis with or without arterial embolization

- Admission and admission into the intensive care unit (ICU)

- Pseudomonas aeruginosa and Aspergillus sp. colonization (defined as at least two results of sputum culture separated by at least 3 months in one year)

- Non-tuberculous mycobacterial infection.

- Others: death, cardiovascular disease (myocardial infarction or stroke).

\section{Statistical analysis}

Statistical analyses were performed with GraphPad Prism 7, using the Kruskal Wallis test for non- parametric values and Chi-squared test for contingencies. For all analyses, $p<0.05$ was considered statistically significant. For demographic and clinical variables, we presented data as median with interquartile range [IQR] for continuous variables and number with percentage for categorical variables.

Lung function change was defined as the difference between first and last tests available. The same method was used for the Bhalla score. In order to take account of differences in follow-up durations and numbers of visits from one patient to another, linear regression (no weighting) was used to find the best-fit value of the slope for FEV1 in each group (expressed as the median [IQR]).

Rate of exacerbation and/or admission was calculated, for each patient, using the number of exacerbations/admissions divided by the duration of follow-up (in year).

In order to identify factors associated with a greater decline in FEV1, univariate and multivariate analyzes were performed from main initial characteristics of the patients, using the online pvalue software (www.pvalue.io).

\section{Results}

Of the 329 adult patients diagnosed with bronchiectasis in our Department between 1984 and 2012, 98 patients fulfilled the study criteria.

\section{Etiologies of bronchiectasis}

The proportion of etiologies was similar between the 98 analyzed patients and the 231 other patients with a shorter follow-up time who were not included (See Flow chart, Fig. 1).

Among the 98 included patients, twenty-three (23.5\%) had post-infectious bronchiectasis, and 16 (16.3\%) idiopathic bronchiectasis.

Twenty (20.41\%) had PID: 13 Common Variable Immune Deficiency (CVID), three IgG-2 subclass deficiency, one dyskeratosis congenita, one hyper IgE syndrome
(STAT3 dominant negative loss of function deficiency) and one patient with interferon- $\gamma$ receptor and interleukin-12 deficiency, one patient each.

The last 39 patients (39.8\%) were suffering from other etiologies including:

- Systemic diseases in twelve patients (12.3\%): four rheumatoid arthritis, one atrophic polychondritis and one Behçet's disease; six patients had ANCA vasculitis: three with bactericidal/permeability increasing protein antibodies, two with anti-myeloperoxidase antibodies and one with anti-Proteinase 3 antibodies.

- We found non-tuberculous mycobacteria infection in five patients (5.1\%): three Mycobacterium avium complex, one Mycobacterium kansasii, and one Mycobacterium shimoidei.

- Chronic respiratory obstructive disease was observed in six patients (asthma: 3; COPD: 3).

- Heterozygous cystic fibrosis transmembrane conductance regulator (CFTR) gene mutation without any other CF manifestation were observed in 4 patients $(4.08 \%)$

- 12 other patients each suffered from another distinct disease, including: previous radiotherapy, renal transplantation, Marfan's disease, HIV infection, primary ciliary dyskinesia, Kartagener's disease, secondary hypogammaglobulinemia, lymphocytic bronchiolitis, bronchopulmonary dysplasia, alpha-1 anti-trypsin deficiency, allergic broncho-pulmonary aspergillosis, tracheo-bronchomalacia

\section{Demographic and baseline characteristics (Table 1)}

Patients were in majority female $(70.4 \%)$. The global median age was 59 years $[47.75 ; 68.25]$; PID patients were slightly younger than patients with idiopathic and post infectious-related bronchiectasis (51.5 years [34.5; 63.3] vs 62 [56; 70], $p=0.02$ ). Most patients (59.2\%) had never smoked, with no significant difference between groups. Patients of the idiopathic and post-infectious group were more likely to have high blood pressure than those of the PID group $(p=0.04)$. There was no statistical difference for other comorbidities.

Most PID patients (85\%) were receiving immunoglobulin substitution (70.6\% intravenous immunoglobulins and 29.4\% subcutaneous Ig) (Table 2). This result is in accordance with the guidelines for the management of these patients [19]. The prescribed posology of immunoglobulin was in median $0.68 \mathrm{~g} / \mathrm{kg} /$ month [0.56;0.92] and median trough level was measured at $10.5 \mathrm{~g} / \mathrm{dl}[10$; 10.92]. Seven patients (17.9\%) among the group "bronchiectasis from other etiologies" were also receiving immunoglobulins because of hypogammaglobulinemia secondary to various immunosuppressive treatments. Azithromycin was given to $52.04 \%$ of patients without difference between 


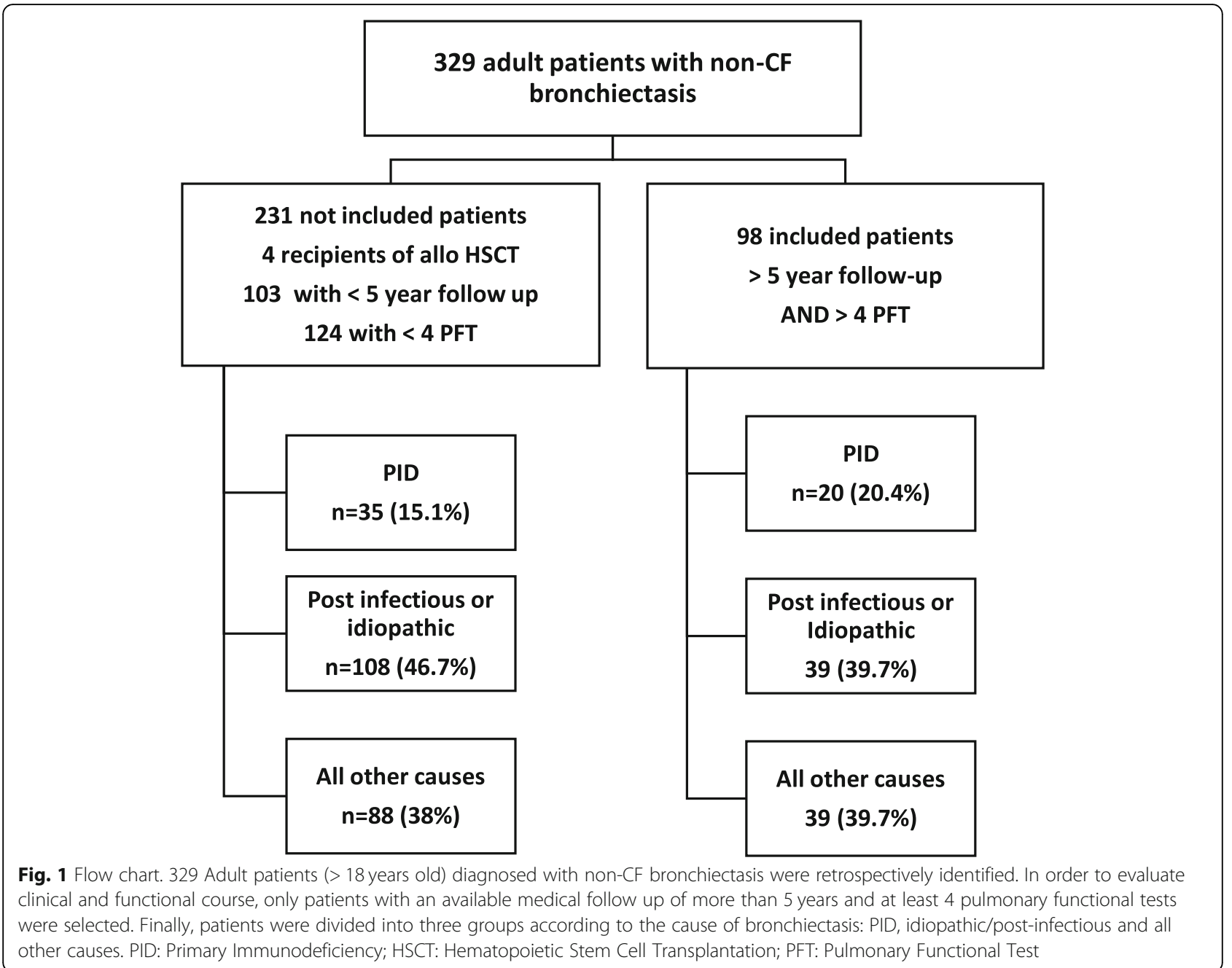

groups $(p=0.78)$. Most patients had mild severity bronchiectasis according to the FACED score (0-2), with no difference between groups $(p=0.25)$ (Table 3). Median FEV1 at diagnosis was $73.5 \%$ of predicted value $[53.8 ; 90.5]$ and $64.3 \%$ of the global population had an obstructive syndrome (FEV1/FVC $<70 \%$ ), without difference between groups $(p=0.53)$. There were more patients with lung distension in PID group than in the idiopathic and post infectious group $(100 \%$ vs $76.2 \%, p=0.02)$.

\section{Outcomes and follow-up (Table 4)}

The overall median follow-up time was 114 months $[84.5 ; 153]$. There were no significant intergroup differences in the length of follow-up or the number of visits including a pulmonary functional test (Table 4).

\section{Pulmonary function tests}

The median [IQR] overall annualized decline in FEV1 was $25.03 \mathrm{~mL}$ [8.16; 43.9], corresponding to an annual decrease of $1.31 \%$ [2.3; 0.1$]$ in the baseline value. In the PID-related group, the median [IQR] decline in FEV1 was $19.82 \mathrm{ml} /$ year [16.08;48.6]. No statistical difference was observed between the three groups for FEV1 variation during the follow up $(p=0.437)$ (Table 4$)$. In a univariate analysis, factors associated with a significant decline of FEV1 (>22 ml/year) were a FACED score more than 3 (OR 1.084 [IC95\%: 1.013;1.33], $p<0.01$ ) and a high mMRC score (OR 1.62 [1.37;1.96], $\mathrm{p}=0$, 044). In a multivariate analysis, only a FACED score of 3 or 4 was still relevant (OR 1.047 [1.004;1.29], $\mathrm{p}<0.01$ ).

\section{Respiratory complications}

Chronic bacterial colonization was found in $44 \%$ of patients: $33.7 \%$ had Pseudomonas aeruginosa and 18.4\% Aspergillus sp (Table 4). Patients from the group "idiopathic and post- infectious bronchiectasis" were more likely to have bacterial bronchial colonization than patients with PID (56.4\% vs $25 \%, p=0.022)$, especially colonization with Pseudomonas aeruginosa (46.2 vs $20 \%$, $p=0.049)$. Rate of exacerbation was not statistically different between groups, with a global median of 0.8 exacerbation per year $[0.3 ; 1.4] \quad(p=0.51)$. Most 
Table 1 Initial clinical data

\begin{tabular}{|c|c|c|c|c|c|}
\hline & $\begin{array}{l}\text { Primary immunodeficiencies } \\
(n=20)\end{array}$ & $\begin{array}{l}\text { Idiopathic and post infectious } \\
(n=39)\end{array}$ & $\begin{array}{l}\text { Other etiologies } \\
(n=39)\end{array}$ & All $(n=98)$ & $P$ value \\
\hline Age (years) & $51.5[34.5-63.25]^{*}$ & $62[56-70]^{*}$ & $59[42-68]$ & $59[47.75-68.25]$ & 0.033 \\
\hline Sex Female/Male & $15 / 5$ & $27 / 12$ & $27 / 12$ & $69 / 29$ & 0.88 \\
\hline BMI $\left(\mathrm{kg} / \mathrm{m}^{2}\right)$ & $20.3[18.25-22.53]$ & 22.9 [19.9-26] & 22 [19.8-25.9] & 21.8 [19.4-25.33] & 0.067 \\
\hline Smoking status & & & & & 0.5 \\
\hline Never & $10(50 \%)$ & $23(59 \%)$ & $25(64.1 \%)$ & $58(59.2 \%)$ & \\
\hline Former & $7(35 \%)$ & $14(36 \%)$ & $9(23.1 \%)$ & $30(30.6 \%)$ & \\
\hline Current & $3(15 \%)$ & $2(5 \%)$ & $5(12.8 \%)$ & $10(10.2 \%)$ & \\
\hline \multicolumn{6}{|l|}{ Comorbidities } \\
\hline Diabetus mellitus & $1(5 \%)$ & $5(12.8 \%)$ & $4(10.3 \%)$ & $10(10.2 \%)$ & 0.64 \\
\hline Gastroesophageal reflux & $7(35 \%)$ & $13(33.3 \%)$ & $20(51.3 \%)$ & $40(40.8 \%)$ & 0.23 \\
\hline Arterial hypertension & $6(30 \%)^{*}$ & $23(59 \%)^{*}$ & $12(30.8 \%)$ & $41(41.8 \%)$ & 0.035 \\
\hline Osteoporosis & $2(10 \%)$ & 7 (17.9\%) & $10(25.6 \%)$ & 19 (19.4\%) & 0.34 \\
\hline IgG initial level (g/l) & $8[6.62 ; 10.75]^{*}$ & $11[10.5 ; 11.5]^{*}$ & $11[9.5 ; 13.5]^{*}$ & $11[9.5 ; 12]$ & 0.0001 \\
\hline Trough level (g/l) & $10.5[10 ; 13]$ & & & & \\
\hline
\end{tabular}

BMI: Body Mass Index

Results expressed as median with interquartile range

exacerbations $(70 \%)$ occurred during autumn or winter. Pneumonitis occurred in $60 \%$ of patients in PID group, with no statistical difference with other patients $(p=0.48)$. Pathogen identification was not achieved in most cases (59.6\%). When recorded, Pseudomonas aeruginosa was the most frequently identified (42.1\%). There were $11(29 \%)$ infections with Hemophilus influenzae and $6(15.8 \%)$ with Streptococcus pneumoniae.

Global median duration of admission was 1.35 days per patient per year $[0.3 ; 5.1]$, without significant difference between groups $(\mathrm{p}=0.4)$.

Intensive care admission for any respiratory complication was necessary for $17.4 \%$ of patients, but only for $5 \%$ in the PID group, without reaching significant difference $(p=0.22)$.

Hemoptysis occurred in 31 patients (31.6\%), including four patients in the PID group (20\%). Broncho-arterial embolization was required in five cases. Among them, four cases (20\%) occurred in PID patients, 14 (31.6\%) in post infectious/idiopathic bronchiectasis and $13(33.3 \%)$ in patients with bronchiectasis of other causes. No patient deceased from hemoptysis. None required pulmonary surgery.

\section{Mortality}

Eleven patients (11.2\%) died: eight from bronchiectasis exacerbation, three from malignancies (non-pulmonary lymphoma, breast and gastric cancer respectively); mortality rate was similar in the three groups. Of note, the patients suffering from lymphoma belonged to the PID group. No patient died due to a cardiovascular cause.

Deceased patients initially presented a higher initial FACED score (27\% patients with a score 5 to 7 vs $3.4 \%$, among survivors $p<0.01$; $36 \%$ with a score $3-4$ vs $15 \%$

Table 2 Treatments

\begin{tabular}{|c|c|c|c|c|c|}
\hline & $\begin{array}{l}\text { Primary immunodeficiencies } \\
(n=20)\end{array}$ & $\begin{array}{l}\text { Idiopathic and post infectious } \\
(n=39)\end{array}$ & $\begin{array}{l}\text { Other etiologies } \\
(n=39)\end{array}$ & All $(n=98)$ & $P$ value \\
\hline Azithromycin & $9(45 \%)$ & $21(53.9 \%)$ & $21(53.9 \%)$ & $51(52 \%)$ & 0.78 \\
\hline Omalizumab & $0^{*}$ & $4(10.3 \%)$ & $7(17.9 \%)^{*}$ & $11(11.2 \%)$ & 0.044 \\
\hline Immunoglobulin substitution & $17(85 \%)^{£}$ & $1(2.6 \%)^{ \pm}$ & $7(17.9 \%)^{£}$ & $25(25.5 \%)$ & $<0.001$ \\
\hline Inhaled treatments & $10(50 \%)$ & $26(66.7 \%)$ & $27(69.2 \%)$ & $63(70.4 \%)$ & 0.32 \\
\hline Corticosteroids & $6(30 \%)$ & $17(43.6 \%)$ & $19(48.7 \%)$ & $42(42.9 \%)$ & 0.39 \\
\hline Long-acting $\beta$-agonist & $9(45 \%)$ & $26(66.7 \%)$ & $25(64.1 \%)$ & $60(61.2 \%)$ & 0.24 \\
\hline Anticholinergic & $4(20 \%)$ & $7(17.9 \%)$ & $9(23.1 \%)$ & $20(20.4 \%)$ & 0.85 \\
\hline Triple association & $2(10 \%)$ & $4(10.3 \%)$ & $4(10.3 \%)$ & $10(10.2 \%)$ & 0.99 \\
\hline Statin use & $1(5 \%)$ & $5(12.8 \%)$ & $10(25.6 \%)$ & $16(16.3 \%)$ & 0.95 \\
\hline
\end{tabular}


Table 3 Initial respiratory data

\begin{tabular}{|c|c|c|c|c|c|}
\hline & $\begin{array}{l}\text { Primary immunodeficiencies } \\
(n=20)\end{array}$ & $\begin{array}{l}\text { Idiopathic and post infectious } \\
(n=39)\end{array}$ & $\begin{array}{l}\text { Other etiologies } \\
(n=39)\end{array}$ & All $(n=98)$ & $P$ value \\
\hline \multicolumn{6}{|l|}{ Lung function } \\
\hline FEV1 (L) & 1.89 [1.59-2.56] & 1.56 [1.16-2.09] & 1.68 [1.28-2.34] & $1.73[1.28-2.20]$ & 0.22 \\
\hline FEV1 (\% predicted) & 75.5 [57.25-92.5] & 73 [54-90] & 66 [51-92] & 73.5 [53.75-90.5] & 0.53 \\
\hline FEV1NC (\%) & 67 [55-76.25] & 62 [52-75] & $64[55-71]$ & 64 [55-74] & 0.71 \\
\hline FEV1NC < 70\% & $12(60 \%)$ & $24(61.5 \%)$ & $27(69.2 \%)$ & $63(64.3 \%)$ & 0.70 \\
\hline $\mathrm{RV} / \mathrm{TLC}>30 \%$ & $20(100 \%)^{*}$ & $30(77 \%)^{*}$ & 35 (89.7\%) & 85 (86.7\%) & 0.002 \\
\hline Bhalla score & $9[6 ; 11]$ & $9[7 ; 11]$ & $9[7 ; 12]$ & $9[7 ; 11]$ & 0.55 \\
\hline FACED score & & & & & 0.6 \\
\hline Mild (0-2) & $16(80 \%)$ & $23(59 \%)$ & $27(69.2 \%)$ & $66(67.3 \%)$ & \\
\hline Moderate (3-4) & $3(15 \%)$ & $12(30.8 \%)$ & $9(23.1 \%)$ & $24(24.4 \%)$ & \\
\hline Severe (5-7) & $1(5 \%)$ & 4 (10.3\%) & $3(7.7 \%)$ & 8 (8.3\%) & \\
\hline
\end{tabular}

FEV1: Forced Expiratory volume in $1 \mathrm{~s}$; VC: Vital Capacity; RV: Residual Volume; TLC: Total Lung Capacity. Results expressed as median with interquartile range

in survivors, $\mathrm{p}<0.01)$ and a lower FEV1 $(1159 \pm 673$ vs $1888 \pm 709 \mathrm{ml}, \mathrm{p}<0.01)$. However, comorbidities and smoking status were equivalent. No patient received a lung transplant nor was registered on the waiting list.

\section{Discussion}

We report here, to our knowledge, the first study on PID-related bronchiectasis compared with a large panel of patients with bronchiectasis of other etiologies.

Table 4 Outcome

\begin{tabular}{|c|c|c|c|c|c|}
\hline & $\begin{array}{l}\text { Primary immunodeficiencies } \\
(n=20)\end{array}$ & $\begin{array}{l}\text { Idiopathic and post infectious } \\
(n=39)\end{array}$ & $\begin{array}{l}\text { Other etiologies } \\
(n=39)\end{array}$ & All $(n=98)$ & $P$ value \\
\hline Follow-up time (months) & $110[87.2 ; 140.5]$ & $122.5[83 ; 156.2]$ & $114[79.5 ; 155.5]$ & $114[84.5 ; 153]$ & 0.92 \\
\hline Number of visits (mean \pm SD) & $9.4 \pm 3.7$ & $9.4 \pm 6.5$ & $10.5 \pm 5.4$ & $9.8 \pm 5.5$ & 0.44 \\
\hline Admission (days/y) & $0.45[0.05 ; 4.675]$ & $1.4[0.7 ; 4.2]$ & $1.6[0.3 ; 6]$ & $1.35[0.3 ; 5.125]$ & 0.4 \\
\hline Admission in ICU & $1(5 \%)$ & $9(23.1 \%)$ & 7 (17.9\%) & $17(17.4 \%)$ & 0.22 \\
\hline Cardiovascular events & 0 & $3(7.7 \%)$ & $3(7.7 \%)$ & $6(6.1 \%)$ & 0.44 \\
\hline Hemoptysis & $4(20 \%)$ & $14(35.9 \%)$ & $13(33.3 \%)$ & $31(31.6 \%)$ & 0.44 \\
\hline Exacerbation rate $(/ y)$ & $0.8[0.525 ; 1.475]$ & $0.6[0.25 ; 1.4]$ & $0.8[0.3 ; 1.5]$ & $0.8[0.3 ; 1.4]$ & 0.51 \\
\hline Pneumoniae & $12(60 \%)$ & $19(52.8 \%)$ & $24(61.5 \%)$ & $55(56.1 \%)$ & 0.48 \\
\hline Chronic colonization & $5(25 \%)^{*}$ & $22(56.4 \%)^{*}$ & $17(43.6 \%)$ & $44(44.9 \%)$ & 0.022 \\
\hline Aspergillus & $2(10 \%)$ & $7(17.9 \%)$ & $9(23.1 \%)$ & $18(18.4 \%)$ & 0.47 \\
\hline Pseudomonas aeruginosa & $4(20 \%)^{\S}$ & $18(46.2 \%)^{\S}$ & $11(28.2 \%)$ & $33(33.7 \%)$ & 0.05 \\
\hline NMT infection & $1(5 \%)$ & $7(17.9 \%)$ & $6(15.4 \%)$ & $14(14.3 \%)$ & 0.39 \\
\hline \multicolumn{6}{|l|}{ Lung function } \\
\hline FEV1 variation (mL/y) & $-19.82[-48.6 ;-16.1]$ & $-22.86[-36.7 ;-4.1]$ & $-28.44[-49.2 ;-11.2]$ & $-25.03[-43.9 ;-8.2]$ & 0.437 \\
\hline FEV1 variation (\%/y) & $-1.345[-2.5 ;-0.48]$ & $-1.08[-1.85 ; 0.34]$ & $-1.5[-2.47 ;-0.15]$ & $-1.31[-2.35 ;-0.10]$ & 0.48 \\
\hline FEV1/NC variation (\%/y) & $-0.605[-1.44 ; 0.46]$ & $-0.3[-1.25 ; 0.39]$ & $-1.00[-1.75 ;-0.27]$ & $-0.55[-1.47 ; 0.24]$ & 0.09 \\
\hline RV/TLC variation (\%/y) & $1.14[0.15 ; 2.5]$ & $0.85[-0.51 ; 2.6]$ & $1,19[-0.44 ; 36]$ & $1.1[-0.06 ; 2.7]$ & 0.81 \\
\hline Bhalla score variation(\%/y) & $0.98[0 ; 2.5]$ & $1[0 ; 2.86]$ & $0.96[0.52 ; 2.77]$ & $0.95[0 ; 2.74]$ & 0.7 \\
\hline Deceased & $2(10 \%)$ & $5(12.8 \%)$ & $4(10.3 \%)$ & $11(11.2 \%)$ & 0.95 \\
\hline Respiratory cause & $1(50 \%)$ & $4(80 \%)$ & $3(75 \%)$ & 8 (72.7\%) & 0.72 \\
\hline
\end{tabular}

ICU: Intensive Care Unit; NMT: non-tuberculous Mycobacterial infection; FEV1: Forced Expiratory Volume in 1 s; VC: Vital Capacity; RV: Residual Volume; TLC: Total Lung Capacity. Results expressed as median with interquartile range. When significant differences were reached, they are shown with a superscript note between the tested groups 
Because all the patients were managed by the same team, it rules out the differences which occur frequently in retrospective multicentric studies. A second point of interest of our study is its long follow up period, with a median time close to 10 years, most previous reported series having a shorter follow up time [14, 20].

Initial data were quite similar between the three groups, except that PID patients were younger. This has already been previously noted with an age in majority less than 50 years in patients with PID-related bronchiectasis [5].

In six recent series of patients with bronchiectasis (16), the percentage of PID patients varied from 1 to $17 \%$. This percentage is higher than in previous studies because of an improvement in PID detection [21-23]. We reviewed a relatively high proportion of patients with PID within our cohort because we are a Reference center for the management of adults with PID and related respiratory diseases.

As PID diagnosis results in specific management, it is important that physicians perform an immunological evaluation of all patients with bronchiectasis. During the same study period, 167 patients were seen in our Department for PID-related pulmonary manifestations. Bronchiectasis were observed in 55 patients (33\%), mainly in CVID (24 patients). Bronchiectasis is known as the first non-infectious manifestation of CVID, reported in 27 to $79 \%$ of patients [10-13]. Patients with CVID should be systematically investigated for bronchiectasis because bronchiectasis is generally isolated whereas granuloma, cytopenia and enteropathy form a set of interrelated features [11].

The prevalence of bronchiectasis is lower in patients with Hyper IgM syndrome than patients with CVID or agammaglobulinemia [10]. Accordingly, patients with Hyper IgM syndrome have a significantly lower risk of non-typeable Hemophilus influenzae carriage (RR 0.39; 95\% CI, 0.21-0.63) [24]. In CVID patients from the European registry, median IgM level was significantly lower in patients with bronchiectasis than others $(0.18 \mathrm{~g} /$ $\mathrm{L}$ vs $0.26 \mathrm{~g} / \mathrm{L}$ respectively) [11]. This may suggest a protective effect of IgM on bronchial disorders.

The hyper IgE syndrome with STAT3 dominant negative loss of function deficiency is another PID in which bronchiectasis is also frequently reported (37.5\%) [25]. Its course is very peculiar, with rapid development of saccular or cystic bronchiectasis after an infectious event [25]. Physicians should analyze serum IgE level in all patients with bronchiectasis and look for extra-pulmonary manifestations that could be related to hyperIgE syndrome. A clinical score has been established by the National Institute of Health [26] to guide molecular analysis. Chronic granulomatous disease, now an adulthood disease, may be rarely a cause of bronchiectasis [27].
Pneumonitis occurred in 60\% patients with PID and exacerbation rate $(0.8$ per patient per year) were similar to what has been observed in other series (7-9). Although bacterial colonization was less frequent in patients with PID (probably due to the immunoglobulin replacement therapy), the frequencies of pneumonitis and exacerbations were similar in the three groups. This may be related to the viral nature of the exacerbations, with viruses observed in 56\% of episodes, as immunoglobulins are only of minor importance in defense against respiratory viruses [28].

Annual decline of FEV1 was calculated at a median of $25.03 \mathrm{ml} / \mathrm{y}$ [8.16;43.9] for all causes of bronchiectasis. This rate was lower than in the study of Buscot et al. [29], reporting a median decrease of $30 \mathrm{~mL}$ per year in 72 patients with non-CF bronchiectasis. This difference could be explained by the fact that our patients had less severe disease at diagnosis (FEV1 $73.5 \%$ in our cohort vs $57 \%$ of predicted values in the one of Buscot et al. [29]). Particularly in PID-related bronchiectasis, the median decline of FEV1 was calculated at $19.82 \mathrm{~mL}$ per year $[16.08 ; 48.6]$ in our study. This is also lower than the one reported by Chen et al. in 37 Australian patients with CVID or X-linked agammaglobulinemia receiving immunoglobulin therapy; they calculated, over a 7.6year-long follow-up, a mean annualized decline of FEV1 of $45 \mathrm{~mL} / \mathrm{y}$ [30]. It is noteworthy that the reported trough level of IgG was lower in this study, at a mean of $7.7 \mathrm{~g} / \mathrm{l}$. However, in another study, Hurst et al. enrolled 33 patients with primary antibody deficiency syndromes (all using immunoglobulin replacement) and calculated a median annual rate of FEV1 decline of $28.2 \mathrm{ml} /$ year which was closer to our observation [31]. Otherwise, a short prospective study analyzing functional course in nine CVID patients with bronchiectasis under immunoglobulins replacement, reported no change in pulmonary function test after a 2-year-follow up [32].

The fact that respiratory function keeps declining despite IgG substitution with high trough IgG level above 8 $\mathrm{g} / \mathrm{dl}$ in patients with predominant antibody deficiency has already been described by our group [10]. It is to be noted that CVID patients with bronchiectasis require higher replacement doses with initial doses of $0,6 \mathrm{~g} / \mathrm{kg} /$ mo [33] while higher doses of IVIG are associated with a smaller decline in lung function [31]. This has been reported to be due to the possible consequence of an increased catabolism in these patients with bronchiectasis but this has not been clearly demonstrated so far [33]. Doses should be adjusted individually and regularly reconsidered in light of infectious recurrences and of occult bronchiectasis occurrence [34]. This observation is in concordance to what was observed in our PID-related bronchiectasis patients who were prescribed in median $0.68 \mathrm{~g} / \mathrm{kg} / \mathrm{month}$ immunoglobulin and presented relatively 
high trough levels of Ig ( $10.5 \mathrm{~g} / \mathrm{dl}$ in median). High-titer Ig replacement therapy meant that the rate of FEV1 decline in patients with PID-related bronchiectasis was the same as in patients with bronchiectasis due to other causes.

Azithromycin is frequently used for management of patients with bronchiectasis as it reduces exacerbations $[35,36]$. Azithromycin has anti-inflammatory properties by decreasing neutrophil recruitment and changing macrophage polarization toward an anti-inflammatory profile [37, 38]. Azithromycin also reduces quorum sensing and biofilm formation of Pseudomonas aeruginosa and non-typeable Hemophilus influenzae biofilms [39-41]. It has been recently suggested that azithromycin reduces the number of exacerbations in PID-related bronchiectasis patients versus patients treated with a placebo [42].

In our study, the mortality rate was $11.2 \%$. Mortality varied, in other studies, from 10 to $30 \%[14,20]$. Most deaths were related to respiratory complications, as it was in other studies but a major difference is the absence of cardiovascular cause of death observed in our patients although it has frequently been evoked for patients with bronchiectasis of all causes [43]. It could be due to the high proportion in our cohort of patients with PID, which are slightly younger than others.

The physiopathology of bronchiectasis in PID patients remains unclear. It has been suggested that patients with PID-related bronchiectasis have a greater airway and systemic inflammation than non PID patients [31]. Hurst et al. showed a greater systemic and local magnitude of inflammatory response in patients with PID-related bronchiectasis and a relationship between FEV1 decline rate and systemic inflammation (serum IL-6 level) [31]. However, in our study, the lung function decline in PID-related bronchiectasis patients (mostly receiving Ig replacement) was similar to that of patients with other causes of bronchiectasis. This suggests that the functional decline may not be secondary to the PID-related humoral deficiency and associated immune disorders but rather to local bronchial chronic inflammation intrinsically associated with airways dilatation by itself.

One may also evoke, in PID-related bronchiectasis as in other causes of bronchiectasis, many other predisposing factors supposed to be involved in airways inflammation such as mannose-binding lectin gene polymorphism or high serum concentration of TNF alpha $[44,45]$. Recently, the role of pulmonary microbiome, the role of matrix metalloproteinases profile and the activation of natural killer cells leading to lung damage [46-48] have been suggested. Other cells may participate in inflammation, such as neutrophils with elastase cathepsin $\mathrm{C}$ or the chemokine receptor CXCR2, macrophages through granulocyte-macrophage colony -stimulating factor (GM-CSF) [49].

\section{Conclusion}

Our study shows that bronchiectasis is frequent in PID patients, highlighting the necessity to perform serum electrophoresis, IgG IgA and IgM serum levels, IgG subclasses and antibodies to Streptococcus pneumoniae to detect a humoral PID in all adult patients with bronchiectasis. It is necessary to collaborate in a multidisciplinary network with immunologists for the diagnosis and the management of patients with PID-related bronchiectasis.

For a long follow up time, the course of PID-related bronchiectasis was similar to bronchiectasis of other causes, in terms of acute infection, annual functional decline and mortality rate. Thus, provided that patients receive Ig replacement, the course of PID-related bronchiectasis seems to be independent of the underlying immune disorder. These observations highlight (i) the protective effect of Ig replacement therapy on respiratory outcomes in patients with PID-related bronchiectasis and (ii) the importance of regularly monitoring the trough Ig level in these patients. However, Ig replacement therapy did not protect fully against lung involvement, and lung function continued to decline in PID patients to the same extent as in patients with bronchiectasis from other causes - suggesting that this functional decline is due to the chronic inflammation caused by airway dilatation, rather than humoral deficiency.

\section{Abbreviations \\ ANCA: anti-neutrophil cytoplasmic antibody; BMI: body mass index; CEREDIH: centre de référence des déficits immunitaires héréditaires; CF: cystic fibrosis; CFTR: cystic fibrosis transmembrane conductance regulator; COPD: chronic obstructive pulmonary disease; CVID: common variable immune deficiency; FEV1: forced expiratory volume in $1 \mathrm{~s}$; ICU: intensive care unit; Ig: immunoglobulin; IVlg: intravenous immunoglobulin; MRC: medical research council; NTM: non-tuberculous mycobacteria; PID: primary immunodeficiency; RV: Residual Volume; TLC: total lung capacity; VC: Vital Capacity}

\section{Acknowledgements}

We are indebted to CEREDIH patients for their participation in this study. We thank Polly Gobin for revising the English language.

\section{Ethics approval and consent to participate}

The study received a favorable opinion from the research protocol evaluation committee of the French Society of Pulmonology "Société de Pneumologie de Langue Française" (CEPRO 2018-018).

\section{Consent for publication}

Not applicable

\section{Availability of data and materials}

The unidentified participant data that support the findings of this study are available from the corresponding author upon reasonable request.

Competing interests

The authors declare that they have no competing interests with the submitted work.

Funding

No funding was received for this research. 


\section{Authors' contributions}

Study design and first draft of the manuscript: H. G, LJ.C. Acquisition, analysis, or interpretation of the data: H. G, LJ. C, H.S., E. C, ML. C, P.D. Critical revision of the manuscript for important intellectual content and approval of last draft: all authors. All authors had full access to the data.

\section{Author details \\ 'Service de Pneumologie, Hôpital Foch, Suresnes, France. ${ }^{2}$ Laboratoire de Pharmacologie Respiratoire UPRES EA 220, Universite Paris Saclay, Versailles, France. ${ }^{3}$ Faculté des Sciences de la Santé Simone Veil, Université Versailles-Saint-Quentin-en-Yvelines, Université Paris Saclay, Versailles, France. ${ }^{4}$ Service de Radiologie, Hôpital Foch, Suresnes, France. ${ }^{5}$ CEREDIH, Centre de Référence des Déficits Immunitaires Héréditaires, Hôpital Universitaire Necker-Enfants Malades, APHP, Paris, France. ${ }^{6}$ Service d'Immunologie-Hématologie et Rhumatologie Pédiatrique, Hôpital Universitaire Necker-Enfants Malades, APHP, Paris, France. 'Institut Imagine, INSERM U1163, Université Paris Descartes-Sorbonne Paris Cité, Paris, France. ${ }^{8}$ Collège de France, Paris, France. ${ }^{9}$ Service d'Hématologie Adulte, Hôpital Necker-Enfants Malades, Assistance Publique-Hôpitaux de Paris, Paris, France. ${ }^{10}$ Service des Maladies Infectieuses et Tropicales, Centre d'Infectiologie Necker Pasteur, Hôpital Necker-Enfants Malades, APHP, Université de Paris, Paris, France.}

Received: 30 July 2019 Accepted: 14 November 2019 Published online: 04 December 2019

\section{References}

1. Pasteur MC, Helliwell SM, Houghton SJ, Webb SC, Foweraker JE, Coulden RA, et al. An investigation into causative factors in patients with bronchiectasis. Am J Respir Crit Care Med. 2000;162(4):1277-84.

2. Shoemark A, Ozerovitch L, Wilson R. Aetiology in adult patients with bronchiectasis. Respir Med. 2007;101(6):1163-70.

3. McShane PJ, Naureckas ET, Strek ME. Bronchiectasis in a diverse US population. Chest. 2012;142(1):159-67.

4. Anwar GA, McDonnell MJ, Worthy SA, Bourke SC, Afolabi G, Lordan J, et al. Phenotyping adults with non-cystic fibrosis bronchiectasis: a prospective observational cohort study. Respir Med. 2013;107(7):1001-7.

5. Lonni S, Chalmers JD, Goeminne PC, McDonnell MJ, Dimakou K, De Soyza $A$, et al. Etiology of non-cystic fibrosis bronchiectasis in adults and its correlation to disease severity. Ann Am Thorac Soc. 2015;12(12):1764-70.

6. King PT, Holdsworth SR, Freezer NJ, et al. Characterisation of the onset and presenting clinical features of adult bronchiectasis. Respir Med. 2006; 100(12):2183-9.

7. Orange JS, Grossman WJ, Navickis RJ, et al. Impact of trough IgG on pneumonia incidence in primary immunodeficiency: a meta-analysis of clinical studies. Clin Immunol. 2010;137(1):21-30.

8. Pourpak Z, Aghamohammadi A, Sedighipour L, Farhoudi A, Movahedi M, Gharagozlou M, et al. Effect of regular intravenous immunoglobulin therapy on prevention of pneumonia in patients with common variable immunodeficiency. J Microbiol Immunol Infect. 2006;39(2):114-20.

9. Aguilar C, Malphettes M, Donadieu J, Chandesris O, Coignard-Biehler H, Catherinot $\mathrm{E}_{\text {, et }}$ al. Prevention of Infections During Primary Immunodeficiency. Clin Infect Dis. 2014;59(10):1462-70.

10. Didier M, Mahlaoui N, Oksenhender E. Pulmonary manifestations in adult patients with primary predominantly humoral immune deficiencies: a Paris area reference network study. Am J Respir Crit Care Med. 2016;193:A1334.

11. Gathmann B, Mahlaoui N, Gérard L, Oksenhendler E, Warnatz K, Schulze I, et al. Clinical picture and treatment of 2212 patients with common variable immunodeficiency. J Allergy Clin Immunol. 2014;134(1):116-126.e11.

12. Oksenhendler E, Gérard L, Fieschi C, Malphettes M, Mouillot G, Jaussaud R, et al. Infections in 252 patients with common variable immunodeficiency. Clin Infect Dis. 2008;46(10):1547-54.

13. Cunningham-Rundles C, Bodian C. Common variable immunodeficiency: clinical and immunological features of 248 patients. Clin Immunol. 1999; 92(1):34-48.

14. Goeminne PC, Nawrot TS, Ruttens D, et al. Mortality in non-cystic fibrosis bronchiectasis: a prospective cohort analysis. Respir Med. 2014;108(2):287-96.

15. Martínez-García MA, Soler-Cataluña J-J, Perpiñá-Tordera M, et al. Factors associated with lung function decline in adult patients with stable noncystic fibrosis bronchiectasis. Chest. 2007;132(5):1565-72.
16. Hill AT, Sullivan AL, Chalmers JD, De Soyza A, Stuart EJ, Floto AR, et al. British thoracic society guideline for bronchiectasis in adults. Thorax. 2019; 74(Suppl 1):1-69.

17. Martinez-Garcia MA, de Gracia J, Vendrell Relat M, Giron R-M, Maiz Carro L de la Rosa CD, et al. Multidimensional approach to non-cystic fibrosis bronchiectasis: the FACED score. Eur Respir J. 2014;43(5):1357-67.

18. Bhalla M, Turcios N, Aponte V, Jenkins M, Leitman BS, McCauley DI, et al. Cystic fibrosis: scoring system with thin-section CT. Radiology. 1991;179(3):783-8.

19. Orange J, Hossny E, Weiler C, Ballow M, Berger M, Bonilla F, et al. Use of intravenous immunoglobulin in human disease: a review of evidence by members of the primary immunodeficiency Committee of the American Academy of allergy, asthma and immunology. J Allergy Clin Immunol. 2006; 117(4):S525-53.

20. Loebinger MR, Wells AU, Hansell DM, Chinyanganya N, Devaraj A, Meister M, et al. Mortality in bronchiectasis: a long-term study assessing the factors influencing survival. Eur Respir J. 2009;34(4):843-9.

21. Lindskog GE, Hubbell DS. An analysis of 215 cases of bronchiectasis. Surg Gynecol Obstet. 1955;100(6):643-50.

22. Glauser EM, Cook CD, Harris GB. Bronchiectasis: a review of 187 cases in children with follow-up pulmonary function studies in 58. Acta Paediatr Scand. 1966:55(Suppl 165):3-16.

23. Landau LI, Phelan PD, Williams HE. Ventilatory mechanics in patients with bronchiectasis starting in childhood. Thorax. 1974;29(3):304-12.

24. Micol R, Kayal S, Mahlaoui N, Beauté J, Brosselin P, Dudoit $Y$, et al. Protective effect of IgM against colonization of the respiratory tract by nontypeable Haemophilus influenzae in patients with hypogammaglobulinemia. J Allergy Clin Immunol. 2012;129(3):770-7.

25. Catherinot $\mathrm{E}$, Givel C, Chandesris $\mathrm{O}$, et al. Pulmonary manifestations in adult patients with STAT3 deficiency: a French nationwide registry-based cohort study [abstract]. Am J Respir Crit Care Med. 2017;195:A4744.

26. Woellner C, Gertz EM, Schäffer AA, Lagos M, Perro M, Glocker E-O, et al. Mutations in STAT3 and diagnostic guidelines for hyper-lgE syndrome. J Allergy Clin Immunol. 2010;125(2):424-432.e8.

27. Salvator H, Mahlaoui N, Catherinot E, Rivaud E, Pilmis B, Borie R, et al. Pulmonary manifestations in adult patients with chronic granulomatous disease. Eur Respir J. 2015:45(6):1613-23.

28. Sperlich JM, Grimbacher B, Workman S, Haque T, Seneviratne SL, Burns SO, et al. Respiratory Infections and Antibiotic Usage in Common Variable Immunodeficiency. J Allergy Clin Immunol Pract. 2018;6(1):159-168.e3.

29. Buscot M, Pottier H, Marquette C-H, Leroy S. Phenotyping adults with noncystic fibrosis bronchiectasis: a 10-year cohort study in a French Regional University hospital center. Respiration. 2016;92(1):1-8.

30. Chen Y, Stirling RG, Paul E, Hore-Lacy F, Thompson BR, Douglass JA. Longitudinal decline in lung function in patients with primary immunoglobulin deficiencies. J Allergy Clin Immunol. 2011;127(6):1414-7.

31. Hurst JR, Workman S, Garcha DS, Seneviratne SL, Haddock JA, Grimbacher B. Activity, severity and impact of respiratory disease in primary antibody deficiency syndromes. J Clin Immunol. 2014;34(1):68-75.

32. de Gracia J, Vendrell M, Alvarez A, Pallisa E, Rodrigo M-J, de la Rosa D, et al. Immunoglobulin therapy to control lung damage in patients with common variable immunodeficiency. Int Immunopharmacol. 2004:4(6):745-53.

33. Lucas M, Lee M, Lortan J, Lopez-Granados E, Misbah S, Chapel H. Infection outcomes in patients with common variable immunodeficiency disorders: relationship to immunoglobulin therapy over 22 years. J Allergy Clin Immunol. 2010;125(6):1354-1360.e4.

34. Bonagura VR, Marchlewski R, Cox A, Rosenthal DW. Biologic lgG level in primary immunodeficiency disease: the lgG level that protects against recurrent infection. J Allergy Clin Immunol. 2008;122(1):210-2.

35. Wong C, Jayaram L, Karalus N, Eaton T, Tong C, Hockey H, et al. Azithromycin for prevention of exacerbations in non-cystic fibrosis bronchiectasis (EMBRACE): a randomised, double-blind, placebo-controlled trial. Lancet Lond Engl. 2012;380(9842):660-7.

36. Altenburg J, de Graaff CS, Stienstra Y, Sloos JH, van Haren EHJ, Koppers RJH, et al. Effect of azithromycin maintenance treatment on infectious exacerbations among patients with non-cystic fibrosis bronchiectasis: the BAT randomized controlled trial. JAMA. 2013;309(12):1251-9.

37. Altenburg J, de Graaff CS, van der Werf TS, Boersma WG. Immunomodulatory effects of macrolide antibiotics - part 1: biological mechanisms. Respir Int Rev Thorac Dis. 2011;81(1):67-74.

38. Cameron EJ, McSharry C, Chaudhuri R, Farrow S, Thomson NC. Long-term macrolide treatment of chronic inflammatory airway diseases: risks, benefits 
and future developments. Clin Exp Allergy J Br Soc Allergy Clin Immunol. 2012;42(9):1302-12.

39. Amsden GW. Anti-inflammatory effects of macrolides - an underappreciated benefit in the treatment of community-acquired respiratory tract infections and chronic inflammatory pulmonary conditions? J Antimicrob Chemother. 2005;55(1):10-21.

40. Lourdesamy Anthony Al, Muthukumaru U. Efficacy of azithromycin in the treatment of bronchiectasis. Respirol Carlton Vic. 2014;19(8):1178-82.

41. Starner TD, Shrout JD, Parsek MR, Appelbaum PC, Kim G. Subinhibitory concentrations of azithromycin decrease nontypeable Haemophilus influenzae biofilm formation and diminish established biofilms. Antimicrob Agents Chemother. 2008;52(1):137-45.

42. Milito C, Pulvirenti F, Tabolli S, et al. A multicenter, double-blind, placebocontrolled randomized clinical trial on I.

43. Navaratnam V, Millett ERC, Hurst JR, Thomas SL, Smeeth L, Hubbard RB, et al. Bronchiectasis and the risk of cardiovascular disease: a populationbased study. Thorax. 2017;72(2):161-6.

44. Litzman J, Freiberger T, Grimbacher B, Gathmann B, Salzer U, Pavlík T, et al. Mannose-binding lectin gene polymorphic variants predispose to the development of bronchopulmonary complications but have no influence on other clinical and laboratory symptoms or signs of common variable immunodeficiency. Clin Exp Immunol. 2008;153(3):324-30.

45. Gregersen S, Holm AM, Fevang B, Ueland T, Sikkeland LIB, Aaløkken TM, et al. Lung disease, T-cells and inflammation in common variable immunodeficiency disorders. Scand J Clin Lab Invest. 2013;73(6):514-22.

46. Rogers GB, Zain NMM, Bruce KD, Burr LD, Chen AC, Rivett DW, et al. A novel microbiota stratification system predicts future exacerbations in bronchiectasis. Ann Am Thorac Soc. 2014;11(4):496-503.

47. Taylor SL, Rogers GB, Chen AC-H, Burr LD, McGuckin MA, Serisier DJ. Matrix metalloproteinases vary with airway microbiota composition and lung function in non-cystic fibrosis bronchiectasis. Ann Am Thorac Soc. 2015; 12(5):701-7.

48. Boyton RJ, Reynolds CJ, Quigley KJ, Altmann DM. Immune mechanisms and the impact of the disrupted lung microbiome in chronic bacterial lung infection and bronchiectasis. Clin Exp Immunol. 2013;171(2):117-23.

49. Chalmers JD, Chotirmall SH. Bronchiectasis: new therapies and new perspectives. Lancet Respir Med. 2018;6(9):715-26.

Ready to submit your research? Choose BMC and benefit from:

- fast, convenient online submission

- thorough peer review by experienced researchers in your field

- rapid publication on acceptance

- support for research data, including large and complex data types

- gold Open Access which fosters wider collaboration and increased citations

- maximum visibility for your research: over $100 \mathrm{M}$ website views per year

At $\mathrm{BMC}$, research is always in progress.

Learn more biomedcentral.com/submissions 